\title{
A participação dos profissionais da medicina na formação da sociedade Sul-Rio-Grandense
}

The participation of medical professionals in the formation of society in Rio Grande do Sul

La participación de los profesionales de Medicina en la formación de la sociedad

en Rio Grande do Sul

Mari Cleise Sandalowski

Renato de Oliveira"

\section{Resumo}

Palco do surgimento da terceira escola médica brasileira, o Rio Grande do Sul viveu um governo radicalmente positivista justamente no período de consolidação da profissão médica na sociedade gaúcha. A aplicação rigorosa dos princípios positivistas à gestão do Estado e da sua relação com a sociedade fez com que, diferentemente das experiências de outros estados brasileiros no mesmo período, aqui os médicos não só não gozassem de qualquer apoio público em suas atividades, como eram igualados, em termos de direito, à multidão de curandeiros que, mesmo sob condições de controle público do exercício da profissão médi$\mathrm{ca}$, abundavam nos outros estados, tanto mais no Rio Grande do Sul. Dessa experiência, que durou exatos quarenta anos, certamente se originaram elementos importantes que marcam a profissão médi- ca no estado. Dentre eles, pode-se citar o peculiar sentido de autonomia do qual estão imbuídos os médicos gaúchos, que se traduz num intenso sentimento corporativo, normalmente associado à ação de suas associações de classe, assim como a pouca importância dada à saúde pública no contexto da maioria das faculdades e cursos de medicina.

Palavras-chave: Memória. Medicina. Sociologia das profissões.

\footnotetext{
Doutora em Sociologia pela Universidade Federal do Rio Grande do Sul. Professora do Departamento de Ciências Sociais e do Programa de Pós-Graduação em Ciências Sociais Universidade Federal de Santa Maria.

** Doutor em Sociologia pela Ecole des Hautes Études en Sciences Sociales. Professor do Programa de Pós-Graduação em Sociologia da Universidade Federal do Rio Grande do Sul.
}

Recebido em: 14/01/2003 - Aprovado em 16/06/2013 http://dx.doi.org/10.5335/hdtv.13n.2.3725 


\section{Introducão}

Sintoma de dependência tecnológica no país, a história das profissões raramente é objeto de estudos sistemáticos entre nós. Empresas de engenharia encerram suas atividades e sua história e experiências tecnológicas são perdidas, não sendo incorporadas criticamente na formação de novos engenheiros. Com a medicina não é diferente. Ainda hoje, acervos documentais de instituições médico-hospitalares e mesmo de escolas médicas são tratados com desdém; às seções de história da medicina, considerada menos importante que as seções "científicas", são reservados cantos obscuros das bibliotecas médicas e não é raro encontrar hospitais já centenários cuja memória depende das lembranças de seus servidores mais antigos.

Nessa situação, a sociedade nacional, como referência concreta de exercício profissional na formação de futuros médicos tende a ser substituída por experiências idealizadas, normalmente associadas aos ambientes onde se produzem as inovações tecnológicas que são incorporadas pela prática médica. É de se supor que tal tendência tenha impacto negativo na identidade dos atuais e futuros médicos, além de contribuir para a depauperação dos padrões éticos do exercício profissional.

Compreender a forma como as mudanças sociais, ao longo do tempo, foram apreendidas e vividas pela categoria médica é fundamental para o entendimento de sua organização enquanto profissão. Recuperar sua memória significa, antes de tudo, perceber as peculiaridades pertinentes a essa categoria e o modo como estas influenciaram a sua relação com a sociedade.

\section{Ainstitucionalização da profissão médica}

Ao longo de muitas décadas os médicos dividiram espaço com curandeiros, feiticeiros, barbeiros, boticários e benzedores no Brasil. Qualquer indivíduo que exercia uma dessas atividades tinha legitimidade para cuidar das enfermidades presentes naquele período. Desse modo, os médicos formados nas universidades europeias desempenhavam determinadas funções, ou seja, enquanto cabia a eles a responsabilidade de prescrever medicamentos e fiscalizar a prática médica, aos barbeiros e cirurgiões destinavam-se as sangrias, cujo caráter manual e feição sangrenta eram considerados como as partes menos nobres da medicina.

As diferentes formas de intervenção do Estado ao longo dos séculos XIX e, principalmente, no século $X X$, e a diversidade de condições históricas ${ }^{1}$ fizeram com que a medicina, ao longo do tempo, se institucionalizasse como profissão. É a partir do século XIX que ela adquire caráter científico, devido à introdução de métodos de produção de conhecimento fundamentados em bases postas pela ciência (SANTOS, 1995). A mudança de mentalidades em relação ao ensino médico, que ocorreu nos Estados Unidos², influenciou a forma de atuação profissional, na qual passa a imperar uma visão mecanicista que concebe o corpo como algo divisível em partes, semelhante a uma máquina.

Essa postura de individualização do objeto está calcada em uma perspectiva cientificista, cuja influência da biologia, da física, da histologia, da microbiologia são fun- 
damentais para essa nova visão de mundo. Diante destas mudanças sociais,

[...] a revolução científica, fruto dos séculos XIX e XX, permitiu grandes avanços no campo das ciências médicas. O conhecimento médico e, consequentemente, a prática profissional adquiriram feições científicas, imprimindo a racionalidade objetiva como fundamento de um novo paradigma médico. $\mathrm{O}$ pensamento e o ato médico fundiram-se numa completa combinação de empirismo, experiência cotidiana e raciocínio clínico" (MACHADO, 1997, p. 25).

Essa reconfiguração no campo profissional influencia a inserção da medicina em importantes dimensões da sociedade, passando a exercitar na esfera das relações de produção tarefas estratégicas. Desse modo, segundo Santos (1995), a medicina assume duas características: de um lado começa a ser identificada como um trabalho profissional técnico, cuja base encontra-se em um conhecimento adquirido por meio do treinamento, e, por outro lado, revela que o médico adapta-se a um conjunto de normas profissionais. Logo, sua base comporta tanto o conhecimento técnico, quanto científico.

\section{Médicos x positivistas: ideários em conflito no Rio Grande do Sul}

Transformadas as condições de formação, mudam também os médicos. A reformulação das escolas de medicina, em 1832, define os limites para o exercício da medicina no Brasil. As atividades de cirurgiões, físicos e boticários passam a ser reunidas em um só corpo, dando início à unidade das atividades médicas. Por consequência, a competência legal sobre a arte de curar passa a ser exclusiva dos médicos que receberam o ensino formal, ou seja, cuja formação deu-se nas faculdades de medicina. O prestígio, a autonomia, o status e o poder que esses profissionais vão adquirindo influenciam na consolidação de seu projeto profissional e de seu caráter corporativo (SANTOS, 1995).

Para Oliveira (1994), o século XIX é caracterizado pela historiografia oficial como um período de grandes transformações positivas no país, pois,

[...] avec l'arrivée de la 'Cour la situation souffre une modification significative. La Famille Royale et as suíte d'aristocrates augmentent de pres d'um tiers la population de Rio de Janeiro. Em plus, il s'installe un contigent important de diplomates, de commerçants étrangers et de familles rurales qui commencent à venir dans cette ville. La pression demographique et les exigences hygiéniques de la nouvelle couche urbaine accélèrent les nécessitée de chagement. La médicine est plus frequentemment sollicitée. Como elle possède des méthodes, des objectifs et des techiniques plus avancées, elle supplante em peude temps l'inefficacité de la bureaucratie' dans la resolution des problèmes de santé de la ville (OLIVEIRA, 1994, p. 26).

Ao mesmo tempo em que, os papéis da medicina são redefinidos ao longo do século XIX, surgem, paralelamente, mudanças no cenário político. A trajetória do país é marcada por fortes conflitos, não somente entre diferentes grupos sociais como também entre o Estado e setores da sociedade civil.

Em relação à medicina, o que se observa a partir de meados de 1800 é uma oposição entre as propostas dos médicos sanitaristas e os personagens políticos formados pelo movimento positivista, os quais eram muito ativos no Congresso Nacional e nas 
campanhas de opinião pública, propagadas pelo Apostolado Positivista do Brasil (OLIVEIRA, 1994).

Os meios militares e a juventude republicana foram, segundo Oliveira (1994), os principais setores em que o positivismo entremeou-se durante a República Velha. Sua doutrina consistia na ideia de liberdade espiritual. Dentre seus princípios pode-se mencionar a liberdade religiosa e o livre exercício profissional.

Analisando a singularidade da história política no Rio Grande do Sul frente às outras regiões e estados brasileiros o embate entre médicos e governo pode ser observado até a década de 1930. Palco de uma revolução antimonarquista, durante o Império, o estado sofreu uma guerra civil logo no início do período republicano, opondo liberais e partidários de uma ditadura que, em nome de ideais republicanos informados pelo positivismo de Auguste Comte, legou ao estado uma expressão que, durante décadas, marcou a política regional: o positivismo castilhista, compreendido como legado político e ideológico de seu líder maior, Júlio de Castilhos.

Justamente no período em que ocorre a consolidação da profissão médica no país, o estado gaúcho vivencia um governo baseado radicalmente no modelo positivista. A aplicação rigorosa desses princípios tanto na gestão do estado quanto da relação que este estabelecia com a sociedade fez com que as atividades de médicos e curandeiros fossem igualadas. Essa experiência que durou aproximadamente quarenta anos culminou na origem de elementos importantes que marcaram a medicina no Rio Grande do Sul, principalmente no que diz respeito ao forte sentimento corporativista e de autonomia entre seus profissionais.

É somente a partir da segunda geração de republicanos, os quais possuíam,

[...] uma visão mais nacional e menos regional da política, menos positivista e mais pragmática e flexível quanto à conduta partidária, (...), [que] as possibilidades de negociação desse grupo sobre os princípios positivistas, como a liberdade profissional, [passam a ser] maiores e mais abrangentes que as da geração anterior (WEBER, 2003, p. 107).

No entanto, o processo de mudança observado não foi automático. Paralelamente à ação desencadeada pelos integrantes do governo estadual, observou-se a atuação de pessoas ilustres da sociedade, como mediadores do diálogo entre a categoria médica e o presidente do estado no período.

Ao mesmo tempo em que se dava o diálogo e as discussões acima mencionadas, grupos de médicos formados, e que atuavam no Rio Grande do Sul, intensificavam suas intervenções, com o objetivo de regulamentar a profissão, a qual era percebida como fundamental para a defesa de seus interesses. A realização do $9^{\circ}$ Congresso Médico Brasileiro em Porto Alegre, em 1926, e a fundação do Sindicato Médico do Rio Grande do Sul, nos anos seguintes, representam alguns dos acontecimentos que indicam as ações exercidas por esses profissionais em relação à liberdade profissional, os quais solicitavam um "[...] decreto que regulamentasse a profissão ao diretor geral da Saúde Pública e [sugeriam] [...] ao governo provisório a necessidade de extinguir a interpretação de liberdade profissional" (WEBER, 
2003, p. 108). Como consequência, inicia-se uma série de ataques contra os "charlatães" e os médicos estrangeiros ${ }^{3}$.

É preciso salientar que a presença de médicos estrangeiros, já numerosos na virada do século, testemunha a mudança do polo econômico do estado, que começa a deslocar-se para a região das colônias. A eles cabia um importante papel na sociedade, sobretudo por difundirem noções e hábitos de higiene nas populações de imigrantes e seus descendentes.

De fato, fortemente identificados com a população que constituía sua clientela, comunicando-se, na maior parte das vezes no mesmo idioma, facilmente se constituíam em referência não apenas profissional, mas, sobretudo, moral. Nas difíceis condições de vida nas colônias até as primeiras décadas do século $X X$, sem qualquer apoio governamental efetivo, os médicos, ao lado de padres e pastores, constituíam as autoridades de fato.

No entanto, a facilidade com que podiam atuar na ausência de qualquer regulamentação da profissão fez com que muitos "falsos médicos" acabassem representando um problema sanitário suplementar. "Médi$\cos ^{\prime \prime}$ guiando-se em cirurgias por livros de anatomia, sustentados por "fraulens" indignadas, operando apendicites sem a retirada do órgão infectado, dentre outros procedimentos igualmente temerários e enganosos, fazem parte de um folclore que encobre um passado pouco glorioso e difícil de ser avaliado em sua extensão real. As aberturas envidraçadas existentes em muitos hospitais do interior construídos nas primeiras décadas do século XX, separando as salas de cirurgia de pequenas salas em que pessoas pudessem observar o que estava ocorrendo com seu familiar na mesa de cirurgia, testemunham um hábito cuja origem está justamente na desconfiança que tais procedimentos geraram nas populações.

É somente em 1938, após a reorganização dos serviços de higiene e saúde pública no estado e da forte campanha de denúncia ao charlatanismo e curandeirismo, que os médicos formados conquistam espaço e são reconhecidos oficialmente, efetivando-se como os únicos profissionais autorizados a exercer a medicina.

\section{A construção do habitus médico}

A forma como ocorreu o processo de construção da profissão médica no Brasil, especialmente no Rio Grande do Sul, foi determinante para a tomada de posicionamentos de seus integrantes, os quais,

[...] têm suas origens em planos mais subjetivos de sua própria trajetória de afirmação de projeto profissional e que, em última análise, concorrem positivamente ou mesmo negativamente para o avanço das reformas necessárias ao setor (SANTOS, 1995, p. 97).

O debate existente entre os médicos brasileiros e o movimento político da sociedade observado no país ao longo das décadas, influenciou de forma decisiva na construção do pensamento moral e ético da categoria profissional. Enfatizando a singularidade da experiência moral na constituição de profissões organizadas em situações sociais específicas, Oliveira (1994) analisa o modo pelos quais os aspectos formais de 
organização profissional concretizam-se historicamente, por meio da incorporação de elementos cujo valor é partilhado entre os indivíduos na constituição de uma sociedade.

A existência de um estado centralizador, alicerçado na anulação da vontade e da autonomia do sujeito social, faz surgir um modelo de ação estrategicamente político, o qual impede de possuir uma ética capaz de engendrar uma verdadeira ética de responsabilidade na condução das negociações com as demais entidades estatais e civis (OLIVEIRA, 1994).

Essas dimensões, observadas no cenário nacional naquilo que se refere à profissionalização do campo médico, são percebidas no debate e na construção da atividade médica, assim como na construção de sua identidade. Para Rego (1995), a discussão sobre o processo de formação do profissional em medicina não pode limitar-se ao debate dos aspectos técnicos unicamente; ao contrário, "[...] ser médico implica estabelecer relações com clientes que necessitam confiar não apenas no conhecimento técnico do profissional, como também ter a certeza de que será respeitado em sua privacidade" (REGO, 199, p. 119).

O relacionamento com os demais colegas sejam eles da mesma especialidade ou pertencentes à moderna equipe de saúde, as experiências vivenciadas em sala de aula e nas aulas práticas, levam a um processo de socialização dos estudantes de medicina. O estabelecimento dessas relações implica numa determinada conduta profissional, embasada em um,
[...] conjunto de ideias, valores e padrões que são compartilhados e transmitidos entre os membros da corporação. Estas normas e padrões definem características de atitudes e condutas técnicas morais, apontando o que é desejável, permitido ou prescrito, codificando os valores da profissão" (REGO, 1995, p. 119-120).

A discussão sobre o processo de socialização do profissional, assim como sobre as habilidades e os conhecimentos adquiridos específicos à área, devem ser analisados pari passu com as experiências que esses sujeitos vivenciam fora dos limites da escola médica e do campo profissional.

Para Moura (2004), a construção do habitus médico pode ser explicada a partir da existência e confluência de uma série de fatores, pelos quais,

[...] a profissão médica instituída apropriou-se progressivamente de um bem social, produzindo um conhecimento de base científica que estrutura uma prática, que tem valor econômico e político e que responde a uma necessidade universal da sociedade, ou seja, uma necessidade que atinge todos seus agentes individualmente (Moura, 2004, p. 19).

Por consequência, a relação entre a medicina, entendida como uma agente social coletivo, e o conjunto da sociedade, são perpassadas por oscilações entre tensões e harmonia, dominação e subordinação, antagonismos e cooperações.

Tal relação com os demais agentes da sociedade (pacientes, demais profissionais da saúde, como enfermeiros, fisioterapeutas, psicólogos, etc.) desencadeia uma apropriação dos saberes adquiridos, fazendo com que a medicina os utilize como uma fonte de poder e “[...] como uma estratégia de do- 
minação e hegemonia no campo da saúde" (MOURA, 2004, p. 19).

Kaufmann (2003), em seu estudo sobre os aspectos condicionantes dos doadores de órgãos, caracteriza as mudanças ocorridas na instituição hospitalar e o modo como isso influencia as relações entre o corpo de profissionais, assim como entre estes e os pacientes. Se, em determinado período, o espaço de curar os doentes era controlado, predominantemente, pelos religiosos, a partir de meados do século $X X$, surge a figura do médico disciplinador, detentor de grande experiência hospitalar.

Essa transição ${ }^{4}$ paradigmática de assistência aos doentes cristaliza as transformações observadas na área da saúde, especialmente naquilo que tange à profissão médica, a qual passa a ser atribuído um papel central de autoridade nos hospitais. Essa autoridade,

[...] ultrapassa a hierarquia administrativa das atribuições e responsabilidades próprias de uma empresa capitalista moderna, do tipo-ideal weberiano de burocracia racional. Poder-se-ia dizer que os médicos detêm ainda uma autoridade do tipo carismático, por possuírem o saber de curar doenças e de salvar vidas. Constroem domínios também por um poder tradicional, derivado de costumes e práticas herdadas, com a legitimidade garantida pela crença de um saber antigo e de certa maneira transcendental (Kaufmann, 2003, p. 29).

Constituídos como autoridades legais no processo de trabalho hospitalar, são os médicos os responsáveis pela determinação do ritmo de trabalho dentro da instituição, assim como sobre os procedimentos e instrumentos utilizados e as decisões sobre casos clínicos. Tendo presente a ideia de que os médicos não se submetem totalmente à estrutura hierárquica, observa-se que,
[...] sendo as aptidões técnicas de caráter pessoal, as amplas possibilidades de determinação dos procedimentos e a natureza multifacetada dos problemas, não existe um domínio fixo de suas ações, acomodando-os em um conceito de autonomia elástica. Nesse conceito, o indivíduo pode dispor de autonomia enquanto possuir o poder de controlar o próprio trabalho e ser responsável pelas ações que realiza, conceito este que se liga a uma perspectiva de independência ética (KAUFMANN, 2003, p. 30).

Esses elementos de ordem subjacente perpassam a prática médica. Desse modo, as novas técnicas e a legalização de suas práticas não são suficientes para conquistar ou impor adesões em relação aos profissionais da medicina, uma vez que esses trazem incorporadas formas de sociabilidade distintas (KAUFMANN, 2003).

Entrelaçado a essa questão encontra-se o atual desenvolvimento científico e tecnológico que, assim como nas demais áreas do conhecimento e das práticas humanas, modifica lentamente a medicina. As profundas transformações ocorridas, ao longo das décadas, no campo do saber e do fazer médico atribuem características específicas. Para Corbellini (2003),

[...] uma prova del fatto che la medicina è oggi caratterizzata, per quanto riguarda le sue base scientifiche, da due diverse filosofie della conoscenza medica emerge abbastanza chiaramente dal dibatto in corso sul significato dell'evidence-based medicine (Ebm). L'Ebm, ovvero la medicina basata sulle prove di efficacia, che nell'ultimo decennio è stata proposta come um nuovo 'paradigma', [...] e assume come metodologia fondamentale per le scelte mediche le prove empiriche ricavate dai trials clinici e dalle metanalisi (CORBELLINI, 2003, p. 221). 
Enquanto o velho paradigma estava centrado na ideia de um bom exercício da prática médica, do conhecimento da fisiopatologia aplicada e da experiência pessoal do médico, como fatores suficientes para a prática médica, a medicina baseada em evidências encontra-se ancorada na validade estatística, rechaçando todo aquele procedimento terapêutico baseado em conhecimento empírico bruto, na intuição ou na tradição. (CORBELLINI, 2003).

Contudo, segundo o estudo de Moura (2004), esses paradigmas entrecruzam-se nos discursos dos profissionais da medicina, pois sua formação congrega não somente o ensino formal como também o aprendizado obtido por meio das experiências individuais e na escola paralela, na qual os estudantes de medicina adquirem conhecimentos práticos e vão formando seu habitus profissional. Essa contradição entre o elogio à ciência positiva de um lado e, de outro, ao "[...] humanismo condescendente em nome do qual alguns procedimentos e condutas baseadas na intuição e na 'experiência' acumulado se justificam plenamente" (MOURA, 2003, p. 148), são legitimados em nome da ideia do médico enquanto pessoa, ou seja, sujeito à interferência de elementos de ordem extracientífica.

Diante de todo esse processo de mudança social a história da medicina congrega elementos singulares para explicar a emergência de personalidades médicas em distintos campos da sociedade, que contribuíram na formação do ideário político e cultural do Rio Grande do Sul.

\section{A participação de médicos na formação do espaço social no Rio Grande do Sul}

Investigar a história da profissão médica não significa apenas compreender a forma como a medicina foi organizada e institucionalizada no Rio Grande do Sul. O estudo dessa temática busca, além disso, apreender o modo como as mudanças sociais foram incorporadas e vividas pela categoria médica e o seu reflexo nos mais distintos campos sociais.

Por meio de relatos orais e do mapeamento de documentos produzidos pelas associações, instituições médico-hospitalares e pelos profissionais ao longo de sua trajetória, foi possível identificar a presença de "personalidades" médicas em distintos campos da sociedade, como o político, o social e o cultural.

Compreendendo o período que vai do século XIX até a primeira metade do século $X X$, foi identificado o envolvimento dos profissionais da medicina em diferentes temas que fizeram parte da história e da formação da sociedade gaúcha.

A participação de médicos na vida político-militar do estado do Rio Grande do Sul é um exemplo da sua presença nas campanhas militares e revolucionárias. Na Revolução Federalista ${ }^{5}$ de 1892 e na Revolução de $1923^{6}$, os médicos se entregaram aos ideais. A Revolução de 1930, também, foi marcada pela atuação de médicos, ora na assistência das populações, ora na política7.

Da mesma forma que se posicionaram frente aos diversos conflitos que permearam o Rio Grande do Sul, a sua atuação na formação do ideário político no estado, também, 
foi marcante. A participação de médicos no período da República como integrantes do Partido Republicano Riograndense é constante como, por exemplo, a participação ativa dos médicos Fernando Abbott e Carlos Barbosa. Ambos disputaram a primeira eleição efetiva da era republicana.

A presença da filosofia positivista nas decisões estatais no Rio Grande do Sul não muda esse cenário. Ao contrário, ela marca um crescente conflito entre governo e médicos, os quais sentiram fortemente os seus efeitos, visto que o referido ideário reinou soberano no governo gaúcho entre 1890 e 1932. Os positivistas recusavam a hierarquia social e distinções que pudessem interferir na liberdade de espírito dos cidadãos, cujo efeito pode ser percebido no adiamento da regulamentação da profissão médica Ao contrário das decisões tomadas pelos demais estados brasileiros, é somente após a Revolução de 1930 que a profissão médica é regulamentada pelo governo gaúcho, fruto do processo de reorganização das relações de trabalho no país. As classes profissionais são estimuladas a organizarem-se em sindicatos e associações, e os médicos não ficam marginais a esse processo.

Assim como nas revoluções, na formação do ideário político no estado e no atendimento médico e organizacional das comunidades de imigrantes, os médicos, também, fizeram-se presentes em outros acontecimentos que marcaram a história do Rio Grande do Sul. Pode-se citar como exemplo a participação dos médicos Protásio Alves e Sarmento Leite na Fundação da Faculdade de Medicina ${ }^{8}$ e Farmácia de Porto Alegre, criada em julho de 1898, ou, então, do Dr. Olinto de Oliveira ${ }^{9}$ responsável pela organização do campo das artes ${ }^{10}$ no estado, não esquecendo de mencionar o fato de que as três primeiras médicas formadas no Brasil foram gaúchas ${ }^{11}$.

\section{Considerações finais}

Governada durante quarenta anos por um regime que se reclamava do positivismo comteano, a sociedade gaúcha viu completado, no período, um longo processo histórico de consolidação de sua identidade regional, coincidindo com o ocaso da sua principal base de sustentação econômica: a economia pastorial da região da campanha. Paralelamente, emergiam novos polos de desenvolvimento nas chamadas regiões coloniais, nas quais as comunidades de imigrantes e seus descendentes constituíam campos simbólicos com pouca ou nenhuma identidade com os mitos fundadores da pátria rio-grandense.

Aintensaatividadeculturaleintelectual do período encontrou poucas instituições capazes de refleti-la em sua diversidade. $\mathrm{O}$ debate entre positivistas e antipositivistas, dominando a cena política e encontrando meios próprios de expressão, principalmente nos jornais partidários e em algumas cátedras das escolas de Medicina, Engenharia e Direito, e refletindo a ilustração própria de intelectuais de província, era pouco sensível às manifestações que começavam a surgir nas regiões de colonização do estado, marcadas, no início, pela atividade de religiosos que asseguravam elos identitários de comunidades com escasso acesso aos meios de cultura do novo século. 
Fazendo parte desse contexto, o médico foi um agente privilegiado na consolidação de formas de sociabilidade, reforçando ou modificando as diferentes estruturas normativas existentes nas distintas regiões do Rio Grande do Sul. Considera-se que os diferentes modelos de sociabilidade, e de atuação dos médicos regionais, desenvolveram-se em virtude das distintas formas de ocupação do território. Enquanto a zona de colonização do estado caracterizou-se pela ocupação com base na pequena propriedade rural, na região da campanha firmaram-se os latifúndios.

Com isso, diferentes formas de sociabilidade foram constituídas. Se nessa última região predominavam a autonomia individual, com exaltação da coragem e da honradez, prevalecendo um modelo aristocrático, a região Norte apresentou características de sociabilidade gregárias, ou seja, as comunidades constituíram seus próprios referenciais, dentro dos quais a noção de liberdade foi acentuada. Estes elementos, por consequência, inferem no papel do médico junto à sociedade, assim como na sua atuação e participação nos diferentes campos sociais.

\section{Abstract}

Rio Grande do Sul, a place where the third Brazilian medical school appeared, had an extremely positivist govern exactly in the consolidation period of medical profession at society from Rio Grande do Sul. Differently from experiences in another Brazilian states in the same period, the rigorous application of positivist principles to State management and its relation with society did not proportionated any public support to doctors in their activities. Besides, concerning rights, they were equal to a great quantity of quacks. Even under public control conditions to carry on doctors profession, quacks abounded in other states specially Rio Grande do Sul. From this experience that lasted exactly 40 years, important elements that marked the medical profession in the state were originated. Among these elements, one can mention the peculiar sense of autonomy from which doctors from Rio Grande do Sul are imbued. It translates an intense corporative feeling that is usually associated to the action of its class associations as well as little importance given to public health in the context of the majority of colleges and courses of medicine.

Keywords: Memory. Medicine. Sociology of professions.

\section{Resumen}

Palco del surgimiento de la tercera escuela médica brasileña, el Rio Grande do Sul vivió un gobernó radicalmente positivista justamente en el periodo de consolidación de la profesión médica en la sociedad sur-riograndense. La aplicación rigurosa de los principios positivistas a la gestión del Estado y su relación con la sociedad hice con que, diferentemente de las experiencias de otros estados brasileños en el mismo período, aquí los médicos no solo no gozaban de cualquier soporte público en sus actividades, como eran igualados, en términos de derecho, a la multitud de curanderos que, mismo bajo condiciones de control público del ejercicio de la profesión mé- 
dica, abundaban en los otros estados, tanto más en Rio Grande do Sul. De esta experiencia, que duró exactos 40 años, ciertamente se originaran elementos importante que marcan la profesión médica en el estado. Entre ellos, se puede apuntar el peculiar sentido de autonomía del cual están imbuidos los médicos sur-riograndenses, lo que se traduce en un intenso sentimiento corporativo, normalmente asociado a las acciones de sus asociaciones de clase, así como la poca importancia direccionada a la salud publica en el contexto de la mayoría de las facultades y cursos de medicina.

Palabras-clave: Memoria. Medicina. Sociología de las profesiones.

\section{Notas}

1 Analisando a realidade brasileira entre o século XIX e início do século XX, Santos (1995) expõe o processo de construção da profissão médica no país. Se, em um primeiro momento, a vinda da família real para o país possibilitou uma ruptura com o período anterior, no qual médicos, charlatães, curandeiros exerciam suas atividades sob iguais condições, instaurando, assim, as prerrogativas necessárias para a fundação das primeiras escolas de medicina, o início do século XX é marcado pelo surgimento do movimento operário nas principais cidades brasileiras. $\mathrm{O}$ deslocamento de parcelas expressivas da população para as grandes cidades exigiu dos trabalhadores formas de organização, a fim de lhes assegurar melhores condições de vida; por consequência, esses fatores sociais exerceram forte influência sobre as profissões liberais, as quais passaram a se mobilizar, com o objetivo de buscar uma representação mais atuante no campo econômico, que passou a ser percebida a partir da criação de diferentes sindicatos.

2 Diante do grande número de escolas médicas existentes nos Estados Unidos no final do século XIX e na primeira década do século subsequente e a precariedade em que se encontravam essas instituições, uma vez que inexistiam critérios referentes ao tempo de duração, formas de ingresso e de formação, dentre outros, fizeram com o governo daquele país encomendasse um estudo com o objetivo de avaliar a situação na qual esses cursos encontravam-se. Dirigido por Flexner e divulgado em 1910, o relatório continha informações que orientavam para a definição de critério e regras comuns para as referidas escolas, aumentando o tempo de formação e uniformizando os padrões de admissão, assim como as grades curriculares dos referidos cursos (SANTOS, 1995).

3 A vinda de médicos estrangeiros ao Rio Grande do Sul se deu à medida que o Império e o governo provincial abriram o estado para a imigração. Muitos eram formados pelas melhores escolas europeias, outros exibiam certificados duvidosos, outros ainda escondiam um passado pouco claro. A maioria integrava-se nas colônias das respectivas etnias, nas vilas e cidades que começavam a surgir no planalto e nas serras do Norte do estado. Favorecia-os a escassez de médicos: até o final do século XIX, praticamente a totalidade dos médicos gaúchos formados pelas faculdades da Bahia e do Rio de Janeiro, ou mesmo da Europa, eram da campanha e da zona Sul. Da mesma forma, os médicos oriundos de outros estados dirigiam-se às cidades da campanha, os polos econômicos e culturais de então.

4 Para Kaufmann (2003), “[...] o paradigma de assistência aos doentes mudava da atitude piedosa, da vantagem da salvação individual, dos privilégios de uma medicina teórica e voltada para o indivíduo para uma medicina social, que atendia também a população em geral, agora sob os estatutos de um estado essencialmente disciplinador" (KAUFMANN, 2003, p. 28-29). Ancorado na perspectiva foucaultiana, o autor analisa o hospital moderno como um resultado histórico dos progressos científicos e das políticas sociais do estado, pois, a partir do período Iluminista, as transformações observadas no conhecimento da arte de curar levantaram um embate entre duas figuras de saberes. Ao contrário da presença de um conflito entre um saber jovem e velhas crenças, ou seja, entre "... um saber prático, herdeiro das assistências acompanhadas dos mestres, dos anos de percepção empírica, da memória e repetição, isto é do exemplo [e] um segundo saber, clínico [o qual] sustentava-se nos atendimentos privilegiados da nobreza, nos domicílios dos bons pagantes e de caráter individual" (KAUFMANN, 2003 , p. 28), estes se confrontam e redefinem-se de acordo com as necessidades existentes no contexto mercantilista do período.

5 Dentre os muitos médicos que atuaram no conflito, destacou-se um baiano, o Dr. Ângelo Dourado.

6 Podem ser citados, nesse caso, os médicos Ramiro Barcellos e Manoel Alla de Lemos.

7 Participaram ativamente desse fato histórico os médicos Antônio Saint-Pastous de Freitas e Elyseu Paglioli, responsáveis pelo Hospital de Sangue numa das regiões de maior conflito: Ja- 
guariaíva, no estado do Paraná, assim como os estudantes de medicina Aureliano de Figueiredo Pinto e Antero Marques, que participaram como capitães-médicos.

8 É preciso destacar que a Faculdade de Medicina e Farmácia de Porto Alegre foi a terceira escola de medicina criada no Brasil. Contudo, há uma diferença fundamental entre a escola as Faculdades de Medicina da Bahia e Rio de Janeiro e a escola médica gaúcha: enquanto as duas primeiras foram instituídas pela Corte quando de sua transferência de Lisboa para o Rio de Janeiro, a terceira foi instituída como faculdade livre, por iniciativa autônoma das corporações profissionais, durante o período republicano.

9 O Dr. Olinto teve intensa atuação no meio profissional. Foi fundador da Faculdade de Medicina e Farmácia de Porto Alegre e seu diretor nos anos 110-1911. Preocupou-se com o apoio logístico para a profissão, fundando o Instituto Pasteur, em 1910, responsável pela vacinação antirrábica, e Oswaldo Cruz, em 1911, para pesquisas em microbiologia, histologia, parasitologia, farmacologia e química, em apoio à Faculdade de Medicina.

10 A criação do Instituto Livre de Belas Artes do Rio Grande do Sul representou uma verdadeira mobilização em todo o estado, com listas de adesões e contribuições percorrendo todos os municípios gaúchos. $\mathrm{O}$ prestígio profissional de seu iniciador, Olinto de Oliveira, fez com que os médicos do estado estivessem, proporcionalmente, entre os mais numerosos aderentes. Araújo Vianna e Libindo Ferras, primeiros diretores respectivamente do Conservatório de Música de Porto Alegre e da Escola de Artes do Instituto, foram por ele pessoalmente escolhidos. Sua visão estratégica sobre o papel da Arte no contexto de uma civilização ficou evidenciada na constituição de uma Comissão Central diretora do Instituto, da qual participaram representantes dos demais cursos superiores livres de Porto Alegre. Aí tomaram assento, dentre outros, Sarmento Leite, representando a Faculdade de Medicina e Farmácia, e André da Rocha, representando a Faculdade de Direito, que se tornou o primeiro Reitor de uma universidade no RS.

11 Rita Lobato, Ermelinda Vasconcelos e Antonieta Cezar Dias são conhecidas como as primeiras mulheres a adquirirem o título de medicina em solo brasileiro.

\section{Bibliografia}

CORBELLINI, Gilberto. Filosofia della medicina. In: HENDRY, Robin. Filosofie delle scienze. Torino: Giulio Einaudi Editore, 2003. p. 213-248.

KAUFMANN, Mauro L. Na fronteira da emancipação e da colonização através do processo de doação de órgãos. 2003. Dissertação (Mestrado em Sociologia) (170 f.). Instituto de Filosofia e Ciências Humanas, Programa de Pós-Graduação em Sociologia, Universidade Federal do Rio Grande do Sul, Porto Alegre, 2003.

MACHADO, Maria Helena et al. Os médicos no Brasil: um retrato da realidade. Rio de Janeiro: FIOCRUZ, 1997.

MOURA, Luís C. S. de. A face reversa da educação médica: um estudo sobre a formação do habitus profissional no ambiente da escola paralela. Porto Alegre: AGE: SIMERS, 2004.

OLIVEIRA, Renato de. Éthique et medecine au Brésil - Etude sur lês rapports entre le débat sur l'éthique médicale et la participation politique dês médecins brésiliens. Paris: Presses Universitaires du Septentrion, 2000. v. 1 e 2.

REGO, Sergio. O processo de socialização profissional da medicina. In: MACHADO, Maria Helena (Org.). Profissões de saúde: uma abordagem sociológica. Rio de Janeiro. FIOCRUZ, 1995. p. 119-132.

SANTOS, Pedro M. Profissão médica no Brasil. In: MACHADO, Maria Helena (Org.). Profissões de saúde: uma abordagem sociológica. Rio de Janeiro. FIOCRUZ, 1995. p. 97-118.

WEBER, Beatriz. Médicos e charlatanismo: uma história de profissionalização no RS. In: SILVA, Mozart Linhares da (Org.). História, medicina e sociedade no Brasil. Santa Cruz do Sul: EDUNISC, 2003. p. 95-128. 